\title{
Tokamak Reactor Systems Studies
}

\author{
Progress Report for the Period \\ November 1, 1991 to October 31, 1992
}

\author{
Fusion Technology Institute \\ University of Wisconsin-Madison
}

August 27, 1992

\section{DISCLAIMER}

\begin{abstract}
This report was prepared as an account of work sponsored by an agency of the United States Government. Neither the United States Government nor any agency thereof, nor any of tiecir employees, makes any warranty, express or implied, or assumes any legal liability or responsibility for the accuracy, completeness, or usefulness of any information, apparatus, product, or process disclosed, or represents that its use would not infringe privately owned rights. Reference herein to any specific commercial product, process, or service by trade name, trademark, manufacturer, or otherwise does not necessarily constitute or imply its endorsement, recommendation, or favoring by the United Siates Government or any agency thereof. The views and opinions of authors expressed herein do not necessarily state or reflect those of the United States Government or any agency thereof.
\end{abstract}




\section{Introduction}

Fusion Technology Institute personnel actively participated in the ARIES project during the present contract period. Numerous presentations were made at ARIES project meetings. several papers were published [1.2. 3.4.5.6], and a very large number of electronic-mail and regular-mail communications were sent. The participation of Fusion Technology Institute engineers and scientists in ARIES meetings is shown in Fig. 1 and a list of presentations is given in Table 1. The remaining sections of this progress report will detail the work accomplished for the ARIES project during the contract period. November 1. 1991 to October 31. 1992. The main areas of effort were

- ARIES-II and ARIES-IV'

1. Neutronics

2. Shield Optimization and Design

3. Safety

4. Systems

5. Startup and Shutdown

6. Ripple Loss

- ARIES-III

7. Contributions to Final Report

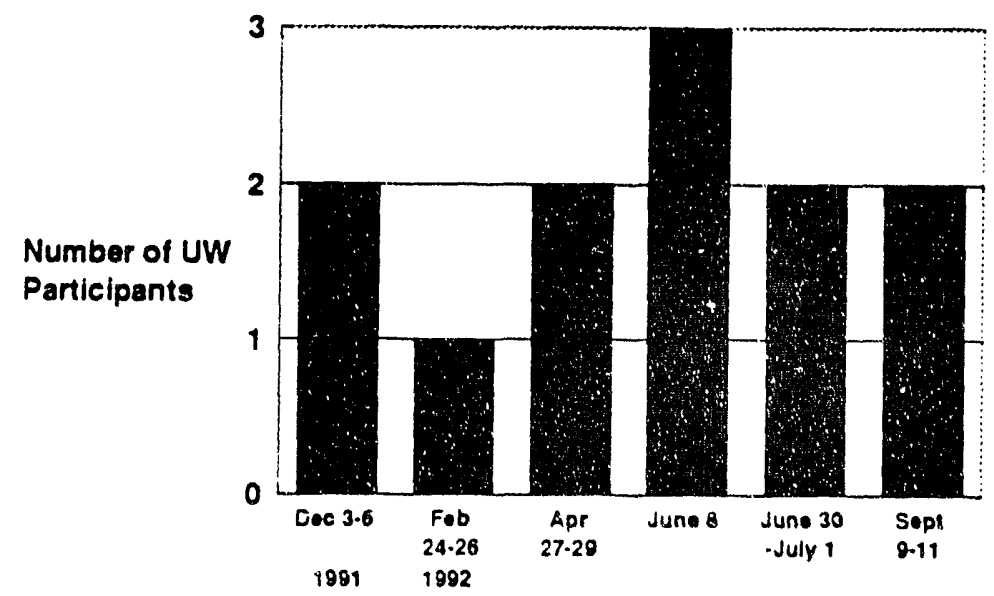

Figure 1: Lniversity of Wisconsin participation in ARIES project meetings. 
Table 1: University of IVisconsin Fusion Technology Institute presentations at ARIES project meetings.

\begin{tabular}{|l|l|l|}
\hline MEETING & ACTHORS & TITLE \\
\hline December 3-6. 1991 & El-Guebaly & Yeutronics Analysis tor ARIES-II and ARIES-IV Designs \\
February 24-26. 1992 & $\begin{array}{l}\text { El-Guebaly } \\
\text { Khater }\end{array}$ & $\begin{array}{l}\text { Shielding and Activation Analysis for ARIES-II } \\
\text { and ARIES-II }\end{array}$ \\
April 27-29. 1992 & El-Guebaly & Tritium Breeding and Shielding Issues \\
$\begin{array}{l}\text { June S. 1992 } \\
\text { (ANS Topical) }\end{array}$ & El-Guebaly & Blanket and Shield Issues \\
June 30-July 1.1992 & El-Guebaly & Shielding Issues and Blanket Neutronics \\
\hline
\end{tabular}

\section{Summary of Tasks Accomplished During FY92}

\subsection{Neutronics}

The extensive, comprehensive calculations necessary for a credible design were performed for both ARIES-II and ARIES-IV in the following areas:

1. First wall and blanket neutronics
(a) Radiation damage
(b) Nuclear heating
(c) Tritium breeding ratio

2. Activation analysis
(a) First wall
(b) Vanadium blanket
(c) Shields

First wall, blanket, and shield neutronics $W_{e}$ calculated nuclear heating, radiation damage. and tritium breeding for both the ARIES-II and the ARIES-IV designs. The nuclear heating was necessary to perform the power cycle thermal hydraulics analysis. Radiation 
damage calculations for $\mathrm{V} . \mathrm{SiC}$. Be. and $\mathrm{C} / \mathrm{C}$-composite stabilizing shell candidates were done to assess the blanket lifetimes. Tritium breeding requirements were accurately evaluated in order to assure that the blanket would provide sufficient tritium to support the fuel cycle. A key conclusion was that it does not appear possible to get net tritium breeding from a solid-breeder blanket without including beryllium in the design. On the other hand, the Li blanket can breed without the need for a neutron multiplier.

Activation analysis The activation of the first wall. blanket. and shield was calculated for the ARIES-II design in order to provide input to the safety and environmental analysis. The activity, biological hazard potential (BHP), decay heat. waste disposal rating (IVDR) and dose after shutdown were computed in detail. Contributions were also made to the analysis of the possibility of recycling the vanadium in ARIES-II.

\subsection{Shield Optimization and Design}

For both the ARIES-II and the ARIES-IV designs, we performed a complete optimization and design of the magnet shields. including evaluation of candidate materials, variation of composition, and computation of radiation effects on the magnets. A key contribution for ARIES-II was the idea that the shield should be split into two parts, with the boundary at the damage level where the outer part would be a full-lifetime component of the reactor. This idea saved considerable cost for the reactor. Shielding requirements around penetrations. such as those of RF antennas and divertors, were also assessed. Parameters for metallic (SS) and $\mathrm{SiC} / \mathrm{SiC}$-composite shields were scoped out. Corresponding algorithms for shield thickness were given to the ARIES systems code group. Optimizing the shield was an ongoing effort throughout the course of the ARIES-II and ARIES-IV designs.

\section{$2.3 \quad$ Safety}

Fusion Technology Institute personnel have been heavily involved in the analysis of ARIES-II and ARIES-IV safety: which is a critical fusion reactor issue. Activities included providing background information and detailed safety analyses. Analysis of activation. waste disposal ratings, afterheat. LOCA. and other safety issues were investigated. A key contribution was the recognition that the highest radioactivity levels may occur before the end-of-life fluence is reached. due to isotopes with short and intermediate half-lives. Thus. the worst-case accident may cause a higher release of radioactivity than the ralue calculated from end-of-life fluences. 


\subsection{Systems}

Lniversity of Wisconsin personnel were active during this contract period in helping benchmark and correct the ARIES sistems code (ASC). Contributions included providing information related to radial builds for ARIES-II and ARIES IV. the blanket lifetime. and other first wall. blanket. and shield areas: periorming detailed checking and commenting on the ARIES systems code (ASC) strawmen: and commenting on the ARIES-III Systems chapter.

\subsection{Startup and Shutdown}

Both startup and shutdown scenarios were defined for the ARIES-II and ARIES-IV tokamak designs. This included generating POPCON plots for the time-dependent profiles of density. temperature. and current required to reach the plasma parameters of the steady-state operating point.

\subsection{Fusion Product Ripple Loss}

In a second-stability tokamak. ripple loss of fusion products is expected to lead to more stringent constraints than in a first-stability tokamak. due to the high rotational transform in the second-stability regime. Fusion Technology Institute personnel pointed out that ripple loss in ARIES-II and ARIES-IV would potentially be a problem, and contributed to the assessment of its effects.

\subsection{Contributions to ARIES-III Final Report}

The ARIES-III Final Report will be published in late 1992 or early 1993 and, although most of the Fusion Technology Institute contributions were finished in FY91, some effort was required to finish a few sections and to read and comment upon other draft chapters for the final report. Final editing and proofreading of Fusion Technology Institute sections will have to be done when the sections are returned from the present editing stage. The sections with Fusion Technology Institute contributions are listed in Table 2.

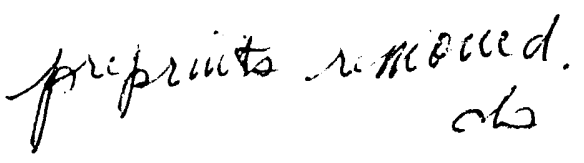


Table 2: Lniversity of Wisconsin Fusion Technology Institute contributions to the ARIES-III Final Report.

\title{
AUTHORS TITLE
}

\author{
Chp. 1: Overview \\ Santarius Sec. 1.3.1: Operating Regime \\ Uittenberg Sec. 1.3.14: Fuel Supplies
}

Santarius Chp. 2: Comparison of First and Second Stability Regimes for D- ${ }^{3}$ He Tokamakis

Chp. 5: Second Stability Transport

Santarius Sec. j.t: Ripple Loss of Fusion Charged Products

Chp. s: Plasma Startup Operations

Emmert Sec. S.2.1: Plasma Kinetics and Power Balance (D- $\left.{ }^{3} \mathrm{He}\right)$

Emmert Sec. \$.3.1: Plasma Kinetics and Power Balance (D-T)

Sawan Sec. S.3.2: Neutron Energy Limit

Chp. 12: First Wall. Shield, and Power Conversion

Blanchard Sec. 12.2.2: Structure Material

Sviatoslavsky Sec. 12.5.1: Flow Configuration

Sviatoslavsky Sec. 12.5.2: First Wall Design and Fabrication

El-Guebaly Sec. 12.6: Magnet Shielding

Sawan Sec. 12.7: Neutronics Analysis

Thater Sec. 12.S: Actiration Analysis

Mogahed Sec. 12.10.3: Thermal Analysis

Blanchard Sec. 12.10.4: Stress Analysis

Santarius Sec. 12.11.1: Adranced Power Conversion Options

Chp. 13: Safety

Sawan. Thater Sec. 13.2: Activation Analysis

Whater Sec. 13.4: Waste Disposal

Wittenberg Chp. 1.5: ${ }^{3} \mathrm{He}$ Fuel Supply 

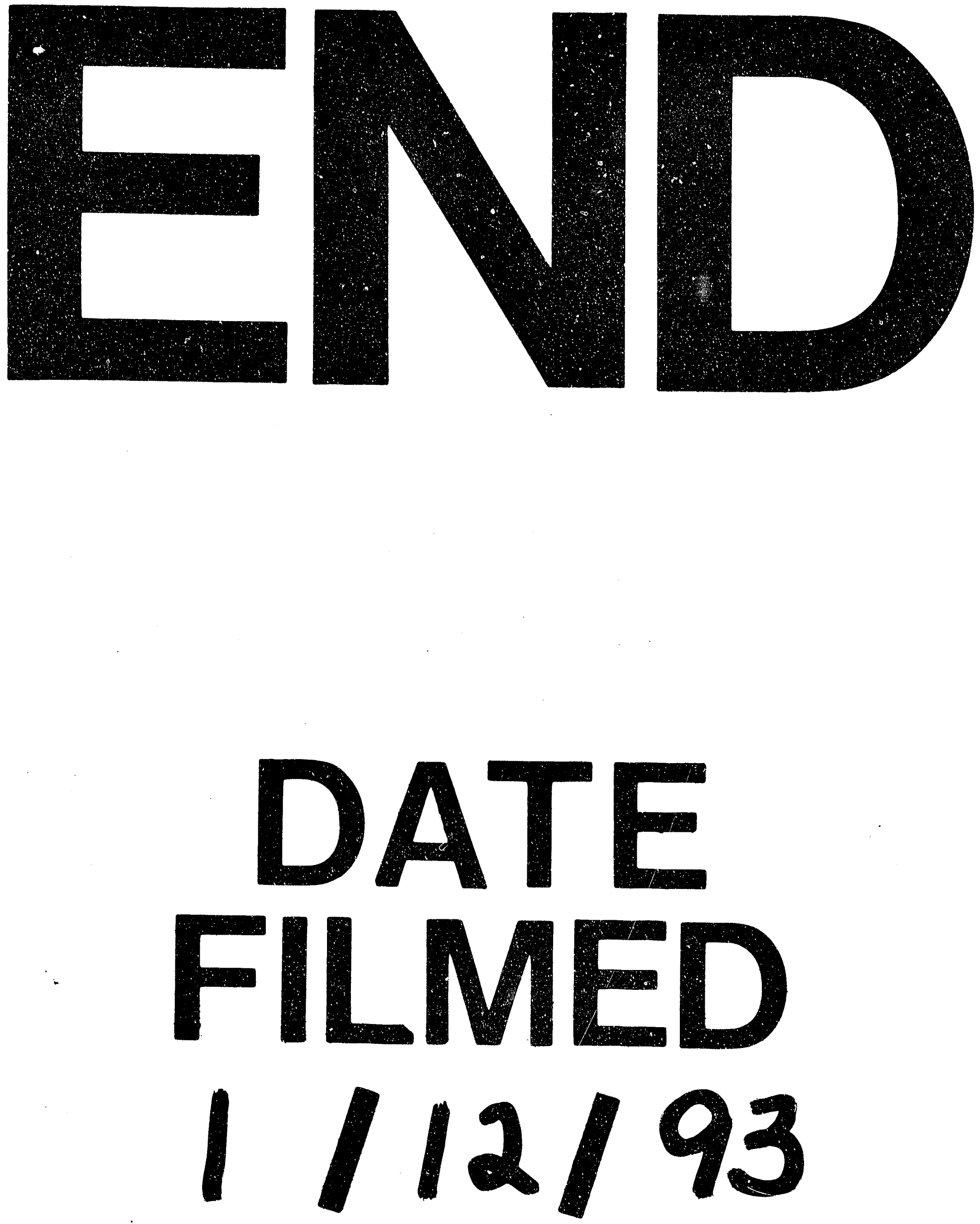
